\title{
An improved quantitative real-time polymerase chain reaction technology for Helicobacter pylori detection in stomach tissue and its application value in clinical precision testing
}

Ling Deng ${ }^{1}$, Xiao-Yi He' ${ }^{1}$ Bin Tang ${ }^{2}$, Yang Xiang ${ }^{1}$ and Juan-Juan Yue ${ }^{1 *}(\mathbb{D}$

\begin{abstract}
Background: Helicobacter pylori (H. pylori) infection is a serious human health threat. The empiric H. pylori treatment paradigm guided by traditional testing technologies has led to antibiotic resistance. Here, we improved the gPCR method to provide technical support for precision H. pylori diagnosis and treatment.

Methods: Two pairs of primers and probes targeting the glmM gene were designed to detect $H$. pylori, and a multiplex GPCR method was established for virulence factor detection. Then, a rapid urease test (RUT), culturing and qPCR were performed on 141 specimens collected from Xinqiao Hospital of China in 2017 to evaluate the qPCR detection capability. Finally, the H. pylori infectious amount and virulence genes were detected by qPCR.

Results: 1 . The improved qPCR method which used two pairs of primers had a higher detection rate (100\%) and better accuracy $(p=0.000)$, compared with the GPCR using a pair of primers. It also had better consistency with the bacterial culture than with RUT (Kappa $=0.440, p<0.001)$. 2. The H. pylori infectious amount was significantly positively associated with gastritis in corpus $(p=0.003)$ and gastric erosion $(p=0.043)$. The $H$. pylori infectious amount in gastric precancerous patients was significantly lower than that in $\mathrm{H}$. pylori-positive patients $(p<0.05)$, and the infectious $\mathrm{H}$. pylori-vacA s1+ amount was significantly greater than that of $H$. pylori-vacA s1- $(p<0.05)$. 3. The vacA s1 frequency was significantly higher than that of vacA $\mathrm{m} 1 / \mathrm{cagA}+/ \mathrm{babA} 2+$ in chronic superficial gastritis $(p=0.000)$, peptic ulcer $(p=0.037)$ and gastric erosion $(p=0.009)$. The $H$. pylori-vacA+/cagA+/babA2+ frequency showed a significant positive correlation $(p<0.05)$.

Conclusions: The H. pylori infectious amount and presence of $H$. pylori virulence factors showed complex correlations with gastric disease occurrence and development. The improved GPCR with good detection performance can be used for quantitative $H$. pylori detection and testing for the virulence genes vacA s1, vacA m1, cagA and babA2 simultaneously. These findings will provide valuable information for disease diagnosis and treatment.
\end{abstract}

Keywords: Quantitative detection, Precision testing, Helicobacter pylori

\footnotetext{
* Correspondence: pettyfeng@hotmail.com

'Department of Clinical Microbiology and Immunology, Faculty of Pharmacy and Medical Laboratory Sciences, Third Military Medical University (Army Medical University), No. 30 Gaotanyan Street, Chongqing 400038, People's Republic of China

Full list of author information is available at the end of the article
}

(c) The Author(s). 2020 Open Access This article is licensed under a Creative Commons Attribution 4.0 International License, which permits use, sharing, adaptation, distribution and reproduction in any medium or format, as long as you give appropriate credit to the original author(s) and the source, provide a link to the Creative Commons licence, and indicate if changes were made. The images or other third party material in this article are included in the article's Creative Commons licence, unless indicated otherwise in a credit line to the material. If material is not included in the article's Creative Commons licence and your intended use is not permitted by statutory regulation or exceeds the permitted use, you will need to obtain permission directly from the copyright holder. To view a copy of this licence, visit http://creativecommons.org/licenses/by/4.0/ The Creative Commons Public Domain Dedication waiver (http://creativecommons.org/publicdomain/zero/1.0/) applies to the data made available in this article, unless otherwise stated in a credit line to the data. 


\section{Background}

Helicobacter pylori ( $H$. pylori) is a bacterial pathogen that infects more than half of the world's population [1]. The infection is associated with gastrointestinal symptomatology, from gastritis to gastric cancer. In 1994, the World Health Organization (WHO) International Agency for Research on Cancer (IARC) classified H. pylori as a group I carcinogen [2]. H. pylori eradication has now been recommended as the primary strategy for preventing gastric cancer in all recently developed guidelines [3-5]. However, empiric drug use under the guidance of traditional detection technology has caused many problems, such as antibiotic resistance, which is becoming increasingly serious [6-8]. In 2019, Barry Marshall suggested that the empiric $H$. pylori treatment paradigm should be changed to test-guided precision treatment [9]. The transformation of the treatment model is based on the development of precision testing technology.

It is necessary to point out that not all carriers develop severe gastrointestinal diseases with clinical symptoms. The genomes of $H$. pylori are heterogeneous and encode different virulence factors that play an important role in the clinical outcome of the infection. Among them, the proteins encoded by the vacA, cagA and babA2 genes determine the pathogenicity of $H$. pylori and have been well described [10].

Vacuolating cytotoxin A (VacA) is a multifunctional toxin. VacA activities, in addition to vacuolation, include interference in the mitochondrial membrane, the stimulation of apoptosis, the blocking of $\mathrm{T}$ cell proliferation and so on, which assists $H$. pylori in colonizing stomach epithelial cells in humans $[11,12]$. The vacA gene has variable structures in the signal region(s), with s1 or s2 allele types, and the intermediate region (i), which has subtypes 1 and 2, while the middle region $(\mathrm{m})$ has $\mathrm{m} 1$ and $\mathrm{m} 2$ allele types. The vacA $\mathrm{s} 1 / \mathrm{i} 1 / \mathrm{m} 1$ allele is thought to secrete an active VacA, which mediates an increased chance of peptic ulceration and leads to the development of gastric cancer [12-14]. Cytotoxin-associated gene A (CagA) is an effector protein encoded by the cagA gene. The cagA gene is localized within a 40-kb chromosomal region known as the cag pathogenicity island (cag-PAI) that consists of 27-31 genes, including those that encode a type IV secretion system (T4SS), which is responsible for the translocation of CagA to the cytoplasm of gastric epithelial cells in cagA-positive strains of $H$. pylori [15]. H. pylori CagA plays a critical role in gastric inflammation and is associated with a significantly increased risk for the development of ulcer disease or gastric cancer $[16,17]$. Another important $H$. pylori virulence factor is the blood group antigenbinding adhesin (BabA), which is one of the bestcharacterized adhesion proteins of the bacterium. It binds to the fucosylated Lewis B antigen (Le b) present on the surface of gastric epithelial cells and facilitates the colonization, persistence of infection and virulence factor release of the bacterium [18]. BabA protein is encoded by the genes babA1 and babA2. Only babA2 encodes the functionally active protein, which is required for the binding of $H$. pylori to Lewis B [19]. Infection with babA2-positive $H$. pylori has been associated with gastric adenocarcinoma, gastric ulcer and duodenal ulcer. The risk of severe disease will increase when it coexists with the cagA gene and the vacA s1 allele $[18,20]$.

Because of its serious harm to human health, the clinical diagnosis $H$. pylori is particularly important. Traditional diagnostic tests are usually divided into invasive and noninvasive methods. Invasive diagnostic tests include endoscopic imaging, histology, a rapid urease test, culture and molecular methods. Noninvasive diagnostic tests included a urea breath test, a stool antigen test and so on [21]. Polymerase chain reaction (PCR) is a molecular method that has been used extensively for the detection of $H$. pylori infection and the evaluation of the virulence factors and antibiotic sensitivity of $H$. pylori $[22,23]$. It has several advantages, such as excellent sensitivity and specificity, fast results and no need for special processing supplies or transportation [21]. However, in contrast to the rapid and highly accurate results obtained by PCR for the detection of $H$. pylori infection and antibiotic-resistant strains, concerns about cost, equipment availability and expertise in molecular techniques inevitably influence the feasibility of PCR in local laboratories and clinical practice [21, 22].

The objective of this research was to improve the quantitative real-time polymerase chain reaction (qPCR) method by designing two pairs of primers and probes targeting the glmM gene to quantitatively detect $H$. pylori and identify for the virulence genes vacA $\mathrm{s} 1$, vacA $\mathrm{m} 1$, cagA and babA2. We also used the method to test for $H$. pylori in patients and analysed the effective information within the data. The method showed a promising clinical application prospect and may be capable of providing a precise clinical diagnosis of $H$. pylori.

\section{Results \\ Performance of qPCR}

A series of 10-fold dilutions of plasmid DNA (ranging from $1 \times 10^{4}$ to $1 \times 10^{9}$ copies $/ \mu \mathrm{L}$ ) were used as the template and tested in quantitative RT-PCRs, all in triplicate.

The detection rate of two pairs of primers (100\%) was higher than that of a pair of primers (15\%). Meanwhile, the mean copy number of the method with a pair of primers $(4.10 \pm 1.09)$ was lower than those of the method with two pairs of primers $(6.57 \pm 0.49)$. The difference was significant $(\mathrm{t}=-9.309, p=0.000)$ (Supplementary Table 1 
and Figure 1). The limit of detection (LOD) of glmM was 100 colony-forming units (CFU), with an average $\mathrm{Ct}$ value of 34.58 , which is equivalent to 6 bacterial copies. The area under the ROC curve (AUC) was 0.988 , and the Youden index was 0.98 . The LODs of vacA s1, vacA m1, cagA and babA2 were $200 \mathrm{CFU}, 100 \mathrm{CFU}, 200 \mathrm{CFU}$ and 100 CFU, respectively. The AUC values were 0.986, 0.988, 0.987 and 0.984 , and the Youden index values were 0.94, $0.95,0.9$ and 0.9 , respectively.

The specificity, sensitivity and positive and negative predictive values (PPVs and NPVs, respectively) of realtime PCR are given in Supplementary Table 2 for all 134 biopsy specimens. In our study, this real-time PCR assay showed a sensitivity of $100 \%$ (NPV, 100\%) and a specificity of $70.5 \%$ (PPV, 40\%).

\section{Determination of $H$. pylori infection status}

By using the criteria adopted for this study, 53 of the 134 (39.6\%) tested patients were positive for $H$. pylori (Supplementary Table 3), and 7 patients were excluded because of only one test result. Of these patients, 20 gave concordant positive results (group I) by all three methods (RUT, qPCR and culturing of $H$. pylori). For another 2 patients (groups II and III), the RUT was not performed or gave negative results, and for another 31 patients (group IV), the culturing gave negative results. However, $H$. pylori was concordantly identified by the remaining two methods.

\section{Comparison of the three methods}

The positive detection rates of the three methods (RUT, qPCR and culture) were $84.3,41$ and $16.4 \%$, respectively. Compared with the RUT method, qPCR had better consistency with the classic gold standard of bacterial culture $($ Kappa $=0.440, p<0.001)($ Table 1$)$.

\section{The quantitative detection of $H$. pylori}

The amount of $H$. pylori in gastric precancerous patients (13.12 \pm 26.56$)$ was significantly lower than that in other $H$. pylori-positive patients $(14,478.11 \pm 43,307.22)$ (Fig. 1a), and the $H$. pylori-vacA s1+ infectious amount $(24,985.20 \pm 55$, 518.99) was significantly higher than the $H$. pylori-vacA s1infectious amount $(580.83 \pm 1451.70)$ (Fig. 1b). The difference was significant $(p<0.05)$. There was no significant difference in copy numbers among different ages, genders,

Table 1 Consistency comparison of qPCR, RUT and culturing

\begin{tabular}{llllll}
\hline & & \multicolumn{2}{l}{ Culture } & Kappa & P (McNemar) \\
\cline { 3 - 4 } & & Positive & Negative & & \\
\hline qPCR & Positive & 22 & 33 & 0.440 & 0.000 \\
& Negative & 0 & 79 & & \\
\multirow{2}{*}{ RUT } & Positive & 20 & 87 & 0.050 & 0.000 \\
& Negative & 1 & 19 & & \\
\hline
\end{tabular}

gastric diseases and genotype strains in $H$. pylori-positive infection patients $(n=53)(P>0.05)$ (Table 2). We also analysed the 134 patients and found that the infectious amount of $H$. pylori was significantly positively associated with gastritis in corpus $(\mathrm{r}=0.259, p=0.003)$ and gastric erosion $(\mathrm{r}=0.175, p=0.043)$.

\section{H. Pylori virulence factor detection}

We found that $58.5 \%(31 / 53)$ of the patients were infected with $H$. pylori containing virulence factors (Supplementary Table 4). The vacA s1 genotype was the most frequent among $H$. pylori-positive patients, with $54.7 \%(29 / 53)$. Among these, $\mathrm{m} 1$ was found in coinfection with s1 in $13.2 \%$ of patients (7/53). In $41.5 \%$ $(22 / 53)$ of the patients, the s1 allele was detected, but the $\mathrm{m} 1$ region was undetectable. Fourteen of the $53 \mathrm{H}$. pylori-positive biopsies were tested for cagA. The babA2 gene was detected in $26.4 \%(14 / 53)$ of $H$. pylori-positive patients. There were no significant differences in the frequency of $H$. pylori-vacA+/cagA+/babA2+ strains among different diseases. However, significant differences were found in the frequency of virulence factors in the same disease (Table 3). Among these variations, the frequency of vacA s1 was significantly higher than that of vacA $\mathrm{m} 1 / \mathrm{cagA}+/ \mathrm{babA} 2+$ in chronic superficial gastritis $(\mathrm{CSG})(p=0.000)$, peptic ulcer $(p=0.037)$ and gastric erosion $(p=0.009)$.

The frequency of $H$. pylori-vacA+/cagA+/babA2+ strains showed a significant positive correlation (Table 4). Among these strains, the babA2 genotype had a higher degree of association with vacA $\mathrm{s} 1(\mathrm{r}=0.459, p=0.001)$ and cagA $(\mathrm{r}=0.418, p=0.002)$ than with vacA $\mathrm{m} 1(\mathrm{r}=0.272$, $p=0.049$ ).

\section{Discussion}

Quantitative RT-PCR is a molecular method of detecting H. pylori that has been recently rapidly developed. Compared with conventional PCR, real-time PCR has several advantages, such as short working time, high specificity, and low risk of contamination. In the past, several target genes, including ureA, glmM, ureC, 16SrRNA, 23SrRNA, hsp60 and vacA, had been used for the detection of $H$. pylori [21]. They are often designed a pair of primers to amplify the target gene; however, it is difficult to amplify all the sequences of $H$. pylori strains due to the large genetic differences and obvious genetic diversity of $H$. pylori, which might lead to false-negative results. The sensitivity of real-time PCR ranges from 63 to 85\% [2426]. We designed two pairs of primers for the conserved target gene glmM, which was the most sensitive and stable gene compared with the other genes, such as rpoB, 16SrRNA and ureA. Compared with a pair of primers, the method had a higher detection rate $(100 \%)$ and better accuracy $(p=0.000)$. The method reduced the 

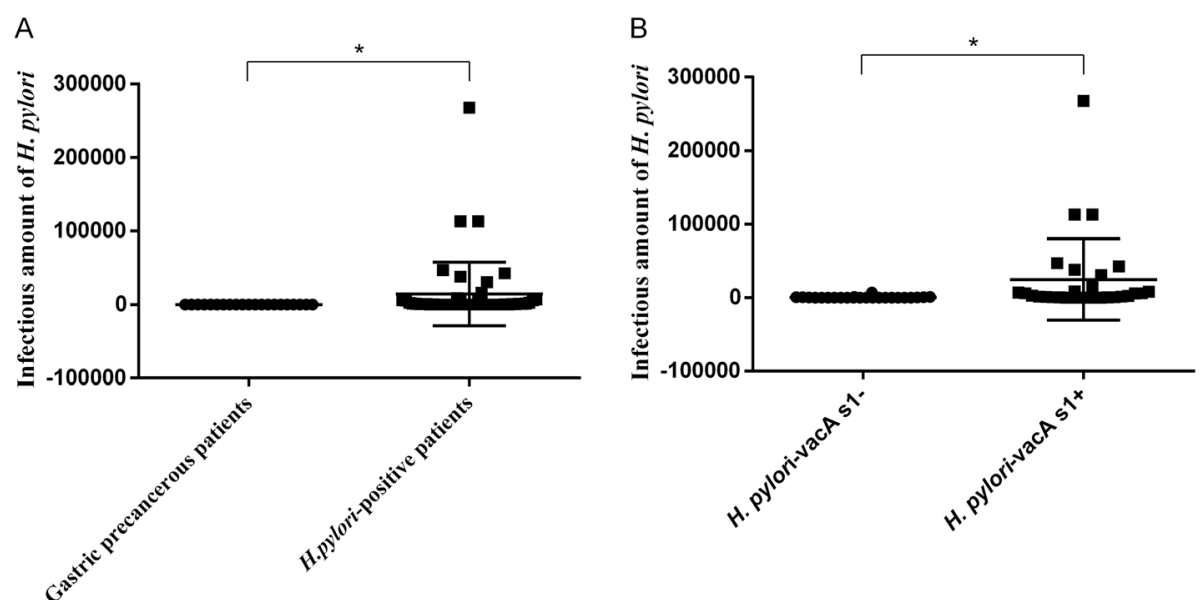

Fig. 1 Comparison of the number of H. pylori copies between different groups. a. Gastric precancerous patients and other $H$. pylori-positive patients. b. The vacA s1- and the vacA $s 1+$ groups. ${ }^{*} p<0.05$

detection limit with a minimum of 6 bacterial copies per $\mu \mathrm{L}$ and increased the sensitivity to $100 \%$. The AUC and Youden index were 0.988 and 0.98 , respectively, which also showed the excellent detection performance of the method. Compared with the common clinical detection method RUT, quantitative RT-PCR showed better consistency with the classic gold standard of bacterial culture. However, the consistency degree was intermediate $(0.41<\mathrm{Kappa}=0.440<0.60)$ [27] because of the low bacterial culture rate $(16.4 \%)$ due to the microaerobic growth characteristics of $H$. pylori strains. PCR was also a convenient method for detecting the cytotoxinassociated genes of $H$. pylori. In previous studies, the vacA, cagA and babA2 genes were tested successfully [18]. However, different primer sequences and reaction conditions were designed to run the PCR many times, which might lead to low throughput and extensive time consumption, so it is difficult to use in clinical practice. We designed a new real-time PCR system that could simultaneously test vacA $\mathrm{s} 1$, vacA $\mathrm{m} 1$, cagA and babA2. It took only 2 to $3 \mathrm{~h}$ from sample processing to test completion and had a good detective capacity (AUC: vacA s1 0.986, vacA m1 0.988, cagA 0.987, babA2 0.984; Youden index: vacA s10.94, vacA m10.95, cagA 0.9, babA2 0.9). The improvement of qPCR that makes it possible to be used in the clinic in the future.

H. pylori is an important human pathogen associated with most cases of peptic ulcer disease, gastritis and gastric cancer. One of the factors contributing to this phenomenon could be the patchy density of $H$. pylori that could be associated with chronic inflammation and activity [28]. Molnar et al. [29] found a significantly increased bacterial density in gastric erosions when compared with the healthy part of the gastric mucosa. Wang and Liu [30] reported that the relative amount of $H$. pylori infection in gastric cancer tissues was significantly higher than that in paracancerous normal tissues. These results confirmed the important relationship between

Table 2 Comparison of $H$. pylori infection among different variables $(n=53)$

\begin{tabular}{|c|c|c|c|c|c|}
\hline Variety & Group & $n$ & Mean $\pm s d$ & $t$ & $p$ \\
\hline \multirow[t]{2}{*}{ Age } & $\leq 50$ & 28 & $20,031.05 \pm 54,049.41$ & 1.106 & 0.274 \\
\hline & $>50$ & 25 & $7105.65 \pm 23,356.77$ & & \\
\hline \multirow[t]{2}{*}{ Gender } & Male & 25 & $16,632 \cdot 10 \pm 53,889.88$ & 0.433 & 0.667 \\
\hline & Female & 28 & $11,525.30 \pm 29,896.31$ & & \\
\hline \multirow[t]{2}{*}{ Gastric disease } & CSG & 45 & $15,287.95 \pm 45,840.75$ & 0.546 & 0.588 \\
\hline & CAG & 8 & $6319.10 \pm 12,921.64$ & & \\
\hline \multirow[t]{6}{*}{ Genotype } & H. pylori-vacA m1+ & 7 & $15,624.29 \pm 18,803.06$ & 0.112 & 0.911 \\
\hline & H. pylori-vacA m1- & 46 & $13,676.97 \pm 45,223.21$ & & \\
\hline & H. pylori-cagA+ & 14 & $21,849.63 \pm 39,784.22$ & 0.809 & 0.423 \\
\hline & H. pylori-cagA- & 39 & $11,092.72 \pm 43,651.55$ & & \\
\hline & H. pylori-babA2+ & 14 & $24,080.55 \pm 39,472.15$ & 1.041 & 0.303 \\
\hline & H. pylori-babA2- & 39 & $10,291.87 \pm 43,517.17$ & & \\
\hline
\end{tabular}


Table 3 The status of the vacA, cagA and babA2 genotypes in patients with gastric diseases

\begin{tabular}{|c|c|c|c|c|c|}
\hline & \multicolumn{4}{|l|}{ Diagnosis } & \multirow{2}{*}{$\begin{array}{l}p \text { value } \\
\left(x^{2} \text { test }\right)\end{array}$} \\
\hline & $\overline{C S G} \mathrm{n}(\%)$ & CAG n(\%) & Peptic ulcer n(\%) & Gastric erosion n(\%) & \\
\hline \multicolumn{6}{|l|}{ H. pylori } \\
\hline Negative & $72(53.7)$ & $9(6.7)$ & $11(8.2)$ & $26(19.4)$ & \multirow[t]{2}{*}{0.509} \\
\hline Positive & 45 (33.6) & $8(6)$ & $10(7.5)$ & $26(19.4)$ & \\
\hline \multicolumn{6}{|l|}{ vacA s1 } \\
\hline Negative & $21(46.7)$ & $3(37.5)$ & $2(20)$ & $12(46.2)$ & \multirow[t]{2}{*}{0.456} \\
\hline Positive & $24(53.3)$ & $5(62.5)$ & $8(80)$ & $14(53.8)$ & \\
\hline \multicolumn{6}{|l|}{ vacA m1 } \\
\hline Negative & $40(88.9)$ & $6(75)$ & $8(80)$ & $23(88.5)$ & \multirow[t]{2}{*}{0.665} \\
\hline Positive & $5(11.1)$ & $2(25)$ & $2(20)$ & $3(11.5)$ & \\
\hline \multicolumn{6}{|l|}{ cagA } \\
\hline Negative & $35(77.8)$ & $4(50)$ & $7(70)$ & $19(73.1)$ & \multirow[t]{2}{*}{0.414} \\
\hline Positive & $10(22.2)$ & $4(50)$ & $3(30)$ & $7(26.9)$ & \\
\hline \multicolumn{6}{|l|}{ babA2 } \\
\hline Negative & $32(71.1)$ & $7(87.5)$ & $6(60)$ & $19(73.1)$ & \multirow[t]{3}{*}{0.638} \\
\hline Positive & $13(28.9)$ & $1(12.5)$ & $4(40)$ & $7(26.9)$ & \\
\hline$p$ value ( $x^{2}$ test $)$ & 0.000 & 0.149 & 0.037 & 0.009 & \\
\hline
\end{tabular}

the bacterial load and the relative diseases. Our results supported that the infectious amount of $H$. pylori was significantly positively associated with gastritis in corpus $(\mathrm{r}=0.259, p=0.003)$ and gastric erosion $(\mathrm{r}=0.175, p=$ 0.043). Interestingly, we found that the amount of $H$. pylori infection in gastric precancerous patients was significantly lower than that in other $H$. pylori-positive patients $(p=0.021)$. Similar results were found in a study by Ladeira et al. [31]. Zhang et al. [32] proposed that atrophic mucosa and intestinal metaplasia are detrimental to the growth of $H$. pylori, and Tang et al. [33] indicated that the cancerous epithelium microenvironment and the changes experienced by cancer cells were detrimental to the survival of the bacteria. These findings suggested that a decrease in $H$. pylori did not necessarily indicate that you are safe from developing cancer but rather that you should undergo regular endoscopies and pay attention to the absolute number of bacteria in your stomach.

Table 4 The correlations between the survival rates of $H$. pylori and the virulence factors

\begin{tabular}{lllll}
\hline & vacA s1 & vacA m1 & cagA & babA2 \\
\hline vacA s1 & 1.000 & & & \\
vacA m1 & $0.355^{* *}$ & 1.000 & & \\
cagA & $0.459^{* *}$ & $0.398^{* *}$ & 1.000 & \\
babA2 & $0.459^{* *}$ & $0.272^{*}$ & $0.418^{* *}$ & 1.000 \\
\hline **p $<0.01{ }^{*} \mathrm{p}<0.05$ & & &
\end{tabular}

On the other hand, in addition to the density of bacteria, the presence of bacterial virulence factors, such as vacA, cagA and babA, at the epithelium would increase H. pylori colonization and the susceptibility to the associated diseases [19]. There have been few studies on the prevalence of $H$. pylori and its vacA, cagA and babA2 genotypes in the Chinese population. Our study showed vacA $\mathrm{s} 1$ to be predominant, with $53.3,80$ and $53.8 \%$ of patients carrying this marker in chronic superficial gastritis, peptic gastric ulcer and erosive gastritis, respectively $(p<0.05)$, which is similar to findings reported elsewhere, such as in South Africa [25], India [34] and Mexico [18]. Some studies mentioned that the prevalence rates of vacAs1 were significantly increased in peptic ulcer [25] and gastric cancer [18]. We did not find the same phenomenon in our studies. There were no significant differences in the prevalence of $H$. pylorivacA $\mathrm{s} 1+/$ vacA $\mathrm{m} 1+/$ cagA+/babA2+ in the different gastritis diseases. Similar findings regarding cagA/babA2 were made in Mexican patients [18], and vacA/cagA had no correlation with pathology in a Nigerian study [35]. Our results suggested that vacA s1 played more important roles in inducing chronic superficial gastritis, peptic ulcer and erosive gastritis than vacA $\mathrm{ml}$, cagA and babA2, which might be partly due to the amount of $H$. pylori significantly increasing when patients were infected with vacA $s 1+$ strains $(p=0.025)$. Although virulence factors and bacterial load are different aspects describing infection, some virulence factors could indeed cause an increase in bacterial load [36]. The specific 
mechanism needs to be further studied. Meanwhile, the frequency of $H$. pylori-vacA+/cagA+/babA2+ strains showed a significant positive correlation. In other words, they often appeared together in the same patients, especially vacAs1, cagA and babA2 $(p<0.01)$. This finding was in accordance with previous reports. vacA s1 was often linked with the presence of the cagA/babA2 genotype, and babA2 status was significantly associated with cagA genotype-positive strains [12, 13, 20, 37, 38]. Therefore, neither of the virulence markers could be considered an independent factor for disease outcome [39]. In fact, when multiple virulence factors were present, the risk of a severe clinical outcome was elevated [40]. In conclusion, the amount of $H$. pylori infection and the $H$. pylori virulence factors showed complex correlations with the occurrence and development of gastric diseases. We should proceed with precision examinations of the infected patients in the clinic to analyse and propose reasonable treatment strategies. All of these findings could be well implemented in the future, along with the improvement in $H$. pylori detection technology by qPCR.

\section{Conclusions}

The H. pylori infectious amount and presence of $H$. pylori virulence factors showed complex correlations with the occurrence and development of gastric diseases. We improved the qPCR method, including designing two pairs of primers and probes to target the glmM gene and establishing a multiplex $\mathrm{qPCR}$ method for virulence factor detection. The method with good detection performance could detect the $H$. pylori infectious amount quickly and accurately and test vacA $(\mathrm{s} 1 / \mathrm{m} 1)$, cagA and babA2 status of $H$. pylori simultaneously; thus, it could be used for precision detection of $H$. pylori. The improved method was used to test $H$. pylori in clinical patients and provided valuable information for disease diagnosis and treatment. First, some patients with a high number of $H$. pylori copies would clearly benefit from antibiotic treatment. Second, these patients should be treated with bacterial eradication therapy as soon as possible, especially those infected with strains carrying the virulence vacA s1 gene or multiple virulence genes simultaneously. Last, we suggest that doctors should focus on patients who have been infected with $H$. pylori in the past but exhibit significantly reduced numbers of bacteria without any treatment. They may have the potential to suffer cancerous development.

\section{Methods}

\section{Patients and specimens}

A total of 141 consecutive patients (83 women and 58 men with an age of $50.94 \pm 12.24$ years) who underwent upper endoscopy due to dyspeptic symptoms at Xinqiao
Hospital, Chongqing, China, during October 2017 and November 2017 were recruited. A rapid urease test (RUT), H. pylori culturing and qPCR were performed on specimens. A patient was considered positive for $\mathrm{H}$. pylori infection when at least two of these three tests gave positive results. A negative $H$. pylori infection status was considered if two of the three tests performed gave concordant negative results.

\section{RUT and culturing of $\mathrm{H}$. pylori}

Two biopsy specimens were taken from different places in the stomach of one patient according to the clinical practice to avoid bleeding. One was sent for RUT, and the other was divided into two pieces for culturing and qPCR.

The RUT was performed using $H$. pylori rapid urease test paper (Zhuhai Kedi Technology Co., Ltd., 151,102) and read within $30 \mathrm{~s}$ for all cases. To culture H. pylori, the biopsy specimens were applied to the surfaces of self-made blood plates ( $200 \mathrm{~mL}$ of Skirrow medium, 3.5 $\mathrm{g}$ of agar powder, $10 \mathrm{~mL}$ of $10 \%$ glucose, $10 \mathrm{~mL}$ of defibrated sheep blood and $1 \mathrm{~mL}$ of composite antibiotic). The inoculated plates were placed in a vertical culture bag (Mitsubishi Gas Chemical Company, Inc. MGC, C43) together with an AnaeroPack (Mitsubishi Gas Chemical Company, Inc. MGC, C-2) to generate a microaerophilic environment $\left(5 \% \mathrm{O}_{2}\right.$ concentration; $10 \% \mathrm{CO}_{2}$ concentration; $85 \% \mathrm{~N}_{2}$ concentration) and incubated for 3 to 5 days. H. pylori microorganisms were identified on the basis of characteristic colony morphology, typical appearance on Gram staining, positive urease and catalase tests, PCR and sequencing.

\section{The process of qPCR \\ DNA extraction}

TRIzol reagent (bioPerfectus technologies, SDK60103) was used to extract total DNA from gastric biopsy sections.

\section{Detection of H. pylori}

The gene glmM was used as a target gene, as it was the most sensitive and stable gene compared with the other genes, such as rpoB, 16SrRNA and ureA (Supplementary Table 5). The sequences of the genes encoding glmM of H. pylori was searched from GenBank. One primer and one probe were designed based on the normal gene sequences. The other primer was designed based on the mutation of $\mathrm{T} 187 \mathrm{C}$ and $\mathrm{A} 189 \mathrm{C}$ in glmM, and the other probe was designed based on the mutation of $\mathrm{C} 231 \mathrm{~T}$ in glmM. Primers and probes were designed using NCBI (https://www.ncbi.nlm.nih.gov/), and synthesized by bioPerfectus Technologies (Shanghai). The sequences of the primers and probes are shown in Table 5. The qPCR system was prepared according to the instructions, and a 
Table $5 \mathrm{glmM}$ primers and probes sequences

\begin{tabular}{ll}
\hline Category & Sequence $\left(5^{\prime} \rightarrow 3^{\prime}\right)$ \\
\hline Forward primer 1(F1) & GCTCTCACTTCCATAGGCTATAATG \\
Forward primer 2(F2) & GCTITAACTTCCATAGGCTATAATGT \\
Reverse primer(R) & GCGCATGTCTCGGTAAAA \\
Probe 1(P1) & FAM-TAGGGCCTATGCCTACCCCTGCGA-HBQ1 ${ }^{\text {a }}$ \\
Probe 2 (P2) & FAM-TAGGGCCTATGCCCACCCCTGC-HBQ1
\end{tabular}

${ }^{\mathrm{a}} \mathrm{FAM}$ is the fluorescence reporter, and $\mathrm{HBQ} 1$ is the fluorescence quencher

total of $25 \mu \mathrm{L}$ was prepared: $12.5 \mu \mathrm{L}$ of $2 \times$ Probe $\mathrm{qPCR}$ Mix, $8 \mu \mathrm{L}$ of primer and probe mix and $4.5 \mu \mathrm{L}$ of template DNA. The qPCR Mix $(12.5 \mu \mathrm{L})$ included FastStart ${ }^{\mathrm{tn}}$ Taq DNA Polymerase (Roche 12,032,937,001, $5 \mathrm{U} / \mathrm{ul}$, $0.2 \mu \mathrm{L}$ ), GeneAmp ${ }^{\text {Tm }}$ PCR Buffer II \& $\mathrm{MgCl}_{2}$ (Applied Biosystems $^{\text {tw }} 4,379,878,5 \times, 5 \mu \mathrm{L}$ ), $\mathrm{MgCl}_{2}$ (Thermo Scientific $^{\mathrm{Tn}}, \mathrm{AB} 0359,25 \mathrm{Mm}, 3 \mu \mathrm{L}$ ), dUTP (Thermo Scientific ${ }^{\mathrm{Tm}}$, R0133, $100 \mathrm{mM}, 0.0625 \mu \mathrm{L}$ ), dTTP (Invitrogen ${ }^{\mathrm{Tx}}$, 10,219, 012, $100 \mathrm{mM}, 0.0625 \mu \mathrm{L}$ ), dATP (Invitrogen ${ }^{\text {тx }}, 10,216$, 018, $100 \mathrm{mM}, 0.125 \mu \mathrm{L}$ ), dGTP (Invitrogen ${ }^{\mathrm{Tw}}, 10,218,014$, $100 \mathrm{mM}, 125 \mu \mathrm{L}$ ), dCTP (Invitrogen ${ }^{\mathrm{nx}}, 10,217,016,100$

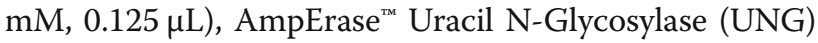
(Applied Biosystems $^{\mathrm{Tx}}$, N8080096, $2 \mathrm{U} / \mu \mathrm{L}, 0.1 \mu \mathrm{L}$ ) and DNase/RNase-free $\mathrm{ddH}_{2} \mathrm{O}$ (Solarbio, R1600, $3.7 \mu \mathrm{L}$ ). The primer and probe mix ( $400 \mu \mathrm{L} / 50$ samples) included $\mathrm{F} 1$ $(100 \mu \mathrm{M}) 3.75 \mu \mathrm{L}, \quad \mathrm{F} 2(100 \mu \mathrm{M}) \quad 3.75 \mu \mathrm{L}, \mathrm{R} \quad(100 \mu \mathrm{M})$ $7.5 \mu \mathrm{L}, \mathrm{P} 1(100 \mu \mathrm{M}) 2.5 \mu \mathrm{L}, \mathrm{P} 2(100 \mu \mathrm{M}) 2.5 \mu \mathrm{L}$ and $380 \mu \mathrm{L}$ of double distilled water. Using a Bio-Rad quantitative real-time fluorescence PCR instrument (CFX96) for PCR amplification, the reaction conditions were as follows: $95^{\circ} \mathrm{C}$ for $3 \mathrm{~min}$ followed by $95^{\circ} \mathrm{C}$ for $10 \mathrm{~s}$ and $58^{\circ} \mathrm{C}$ for $40 \mathrm{~s}$ for a total of 45 cycles. The PCR product was stored at $4{ }^{\circ} \mathrm{C}$. The average value of the experiment was obtained from the assay repeated three times.

\section{Quantifying H. pylori}

The detailed quantitative steps are described in the supplementary files. In short, we used house-keeper gene GAPDH as an internal control. First, the plasmid PUC57-GAPDH which contains the GAPDH gene (Synthesized by Shanghai Sangon Biotech) was quantified by qPCR with the Human DNA Quantitation Standard (NCBI, SRM2372) as the reference standards, and the copy number of GAPDH on the plasmid which was equal to that of $\mathrm{AMP}^{\mathrm{r}}$ contained in PUC57 was calculated. Second, the different concentrations of the plasmid PUC57-GAPDH with a known copy number were quantified by $\mathrm{qPCR}$ with the primer and probe of $\mathrm{AMP}^{\mathrm{r}}$ to obtain the quantitative formula. The formula was used to calculate the number of copies of PUC57-glmM (Synthesized by Shanghai Sangon Biotech), which was quantified by qPCR with the primer and probe of $\mathrm{AMP}^{\mathrm{r}}$. Last, the plasmid PUC57- glmM with a known copy number was quantified by qPCR with the primer and probe of glmM. According to the test result, the following calculation formula could be obtained: $\mathrm{Ct}=-3.4 \times \log$ (copies $/ \mu \mathrm{L})+37.18\left(\mathrm{R}^{2}>0.99\right)$. This method could be used to quantify other samples (Supplementary Tables 6-11).

Table 6 The primers and probe sequences for the virulence factors

\begin{tabular}{|c|c|c|}
\hline Virulence Factor & Category & Sequence $\left(5^{\prime} \rightarrow 3^{\prime}\right)^{\mathbf{a}}$ \\
\hline \multirow[t]{4}{*}{ vacA s1 } & Forward primer (F) & ACACCGCAAAATCAATCGCC \\
\hline & Reverse primer (R) & CCCCAACAATGGCTGGAATG \\
\hline & Probe 1 (P1) & HEX-GCATCACACCGCAACAAAGT-BHQ2 \\
\hline & Probe 2 (P2) & HEX-GCGCCATACCGCAAGAGAGT-BHQ2 \\
\hline \multirow[t]{5}{*}{ vacA m1 } & Forward primer 1 (F1) & ATCAATTATTTGGTCCGAGGC \\
\hline & Forward primer 2 (F2) & ATCAACTATCTGGTCCGAGGC \\
\hline & Reverse primer (R) & GCTGTTAATCTTCATGAGCGGT \\
\hline & Probe 1 (P1) & FAM-GATAGCGCGACTGGGTTTAA-BHQ1 \\
\hline & Probe 2 (P2) & FAM-GACAGCGCGACCGGATTTTA-BHQ1 \\
\hline \multirow[t]{3}{*}{ cagA } & Forward primer (F) & GTGCCTGCTAGTTTGTCAGC \\
\hline & Reverse primer (R) & ACGAGCTTAAGCCACTCAGG \\
\hline & Probe 1 (P) & Texas Red-GCTATTAACAGCCACACACGC-Dabcyl \\
\hline \multirow[t]{4}{*}{ babA2 } & Forward primer (F) & GAAATCCCTAATACTAAATCC \\
\hline & Reverse primer (R) & GTAAAAGCCGTCGTCTTCAGC \\
\hline & Probe 1 (P1) & CY5-GGAGAAAAAACATGAAAAAACA-BHQ3 \\
\hline & Probe 2 (P2) & CY5-GGGGAGAAAACATGAAAAAACA-BHQ3 \\
\hline
\end{tabular}




\section{Detection of the virulence factors of $\mathrm{H}$. pylori}

GenBank was searched for the sequences of the genes encoding vacA s1, vacA m1, cagA and babA2 of $H$. pylori. The probes of vacA s1 were designed based on the two genotypes of vacA s1 (vacA sla and vacA s1b). The forward primer 2 of vacA $\mathrm{m} 1$ were designed based on the mutation of $\mathrm{T} 2037 \mathrm{C}$ and $\mathrm{T} 2041 \mathrm{C}$, and the probe 2 of vacA $\mathrm{m} 1$ was designed based on the mutation of T2115C, T2124C and T2127A. The primer and probe of cagA were designed based on the normal gene sequences. The probe 2 of babA2 was designed based on the mutation of A283G and A286G. Primers and probes were designed by using NCBI (https://www.ncbi.nlm.nih. gov/). Primers and probes were synthesized by Sangon Biotech (Shanghai). The sequences of primers and probes are shown in Table 6. The real-time PCR system was prepared according to the instructions, and a total of $25 \mu \mathrm{L}$ was prepared: $12.5 \mu \mathrm{L}$ of $2 \times$ Probe qPCR Mix, $8 \mu \mathrm{L}$ of primer and probe mix and $4.5 \mu \mathrm{L}$ of template DNA. The primer and probe mix $(400 \mu \mathrm{L} / 50$ samples $)$ included vacA s1: F $(100 \mu \mathrm{M}) 7.5 \mu \mathrm{L}, \mathrm{R}(100 \mu \mathrm{M}) 7.5 \mu \mathrm{L}$, P1 $(100 \mu \mathrm{M}) 5 \mu \mathrm{L}$, P2 $(100 \mu \mathrm{M}) 5 \mu \mathrm{L}$; vacA m1: F1 $(100 \mu \mathrm{M}) \quad 3.75 \mu \mathrm{L}, \quad \mathrm{F} 2(100 \mu \mathrm{M}) 3.75 \mu \mathrm{L}, \mathrm{R}(100 \mu \mathrm{M})$ $7.5 \mu \mathrm{L}, \mathrm{P} 1(100 \mu \mathrm{M}) 5 \mu \mathrm{L}, \mathrm{P} 2(100 \mu \mathrm{M}) 5 \mu \mathrm{L} ;$ cagA: F $(100 \mu \mathrm{M}) 7.5 \mu \mathrm{L}, \mathrm{R}(100 \mu \mathrm{M}) 7.5 \mu \mathrm{L}, \mathrm{P}(100 \mu \mathrm{M}) 5 \mu \mathrm{L}$; babA2: $\quad \mathrm{F} \quad(100 \mu \mathrm{M}) \quad 7.5 \mu \mathrm{L}, \quad \mathrm{R} \quad(100 \mu \mathrm{M}) \quad 7.5 \mu \mathrm{L}, \quad \mathrm{P} 1$ $(100 \mu \mathrm{M}) 5 \mu \mathrm{L}, \mathrm{P} 2(100 \mu \mathrm{M}) 5 \mu \mathrm{L}$ and $305 \mu \mathrm{L}$ of double distilled water. Using the Bio-Rad quantitative real-time fluorescence PCR instrument (CFX96) for PCR amplification, the reaction conditions were as follows: $95^{\circ} \mathrm{C}$ for $3 \mathrm{~min}$, followed by $95^{\circ} \mathrm{C}$ for $10 \mathrm{~s}$ and $51^{\circ} \mathrm{C}$ for $40 \mathrm{~s}$ for a total of 40 cycles. The PCR product was stored at $4{ }^{\circ} \mathrm{C}$. The average value of the experiment was obtained from the assay repeated three times.

\section{Statistical analyses}

SPSS13.0 for Windows (SPSS, Inc., Chicago, IL) was used for statistical analysis of data. Measurement data were analysed by $t$-test and $x^{2}$ test. The $t$-test was expressed as the mean \pm standard deviation. Kappa and McNemar tests were used to compare consistency between different $H$. pylori detection methods. Productmoment correlation was used to analyse the relationship between different variables. $P<0.05$ was considered statistically significant.

\section{Supplementary information}

Supplementary information accompanies this paper at https://doi.org/10. 1186/s12896-020-00624-z.

Additional file 1: Supplementary Fig. 1. Comparison of copy number between two primer design strategies. Supplementary Table 1. The sequences of a pair of primers and probe for glmM. Supplementary Table 2. Performance of quantitative RT-PCR testing $H$. pylori. Supplementary Table 3. Determination of $H$. pylori infection status in 141 patients. Supplementary Table 4. H. pylori virulence factor detection in patients. Supplementary Table 5. The detection results of glmM, rpoB, 16SrRNA and ureA. Supplementary Table 6. GAPDH primers and probe sequences (138 bp). Supplementary Table 7. The quantitative results of PUC57-GAPDH. Supplementary Table 8. AMP ${ }^{r}$ primers and probe sequences $(110 \mathrm{bp})$. Supplementary Table $\mathbf{9}$. The quantitative results of AMP' $^{r}$. Supplementary Table $\mathbf{1 0}$. The quantitative results of PUC57$\mathrm{glmM}$. Supplementary Table 11. The quantitative results of glmM.

\section{Abbreviations}

H. pylori: Helicobacter pylori; RUT: Rapid urease test; VacA: Vacuolating cytotoxin A; CagA: Cytotoxin-associated gene A; BabA: Blood group antigenbinding adhesion; PCR: Polymerase chain reaction; qPCR: Quantitative realtime polymerase chain reaction; LOD: Limit of detection; AUC: Area under the ROC curve; CFU: Colony-forming unit; NPV: Negative predictive values; PPV: Positive predictive values

\section{Acknowledgements}

We thank the members of Gastroenterology Department, Xinqiao Hospital, Chongqing, China, for the collection of the gastric biopsy specimens.

\section{Authors' contributions}

JjY conceived and designed the study; LD and XyH performed the experiments; JjY, BT and YX analysed the data; JjY and BT wrote the manuscript. All authors have read and approved the manuscript

\section{Funding}

This work was supported by grants from National Natural Science Foundation of China (NSFC, 81601832). The funders had no role in the design of the study and collection, analysis, and interpretation of data and in writing the manuscript.

\section{Availability of data and materials}

All data involved in this study is available upon reasonable request to the corresponding author.

\section{Ethics approval and consent to participate}

The study was approved by the Institutional Review Board at Army Medical University, and all patients signed an informed consent form before participation. All experiments involving human subjects were performed in accordance with the World Medical Association's Declaration of Helsinki (1964 and its later amendments).

Consent for publication

Not applicable.

\section{Competing interests}

The authors declare that they have no competing interests.

\section{Author details}

${ }^{1}$ Department of Clinical Microbiology and Immunology, Faculty of Pharmacy and Medical Laboratory Sciences, Third Military Medical University (Army Medical University), No. 30 Gaotanyan Street, Chongqing 400038, People's Republic of China. 'Department of Digestive Disease Center, The Third Affiliated Hospital of Chongqing Medical University (General Hospital), Chongqing, China.

Received: 8 December 2019 Accepted: 19 May 2020

Published online: 22 June 2020

References

1. Hooi JKY, Lai WY, Ng WK, Suen MMY, Underwood FE, Tanyingoh D, et al. Global prevalence of Helicobacter pylori infection: systematic review and meta-analysis. Gastroenterology. 2017;153:420-9.

2. International Agency for Research on Cancer. Schistosomes, liver flukes and Helicobacter pylori. Lyon, France: International Agency for Research on Cancer; 1994.

3. El-Serag HB, Kao JY, Kanwal F, Gilger M, LoVecchio F, Moss SF, et al. Houston consensus conference on testing for Helicobacter pylori infection in the United States. Clin Gastroenterol Hepatol. 2018;16:992-1002.e6. 
4. Sugano K, Tack J, Kuipers EJ, Graham DY, El-Omar EM, Miura S, et al. Kyoto global consensus report on Helicobacter pylori gastritis. Gut. 2015;64:135367.

5. Liu WZ, Xie $Y$, Lu H, Cheng $H$, Zeng ZR, Zhou LY, et al. Fifth Chinese national consensus report on the management of Helicobacter pylori infection. Helicobacter. 2018;23:e12475.

6. Saracino IM, Zullo A, Holton J, Castelli V, Fiorini G, Zaccaro C, et al. High prevalence of primary antibiotic resistance in Helicobacter pylori isolates in Italy. J Gastrointestin Liver Dis. 2012;21:363-5.

7. Shiota S, Reddy R, Alsarraj A, El-Serag HB, Graham DY. Antibiotic resistance of Helicobacter pylori among male United States veterans. Clin Gastroenterol Hepatol. 2015;13:1616-24.

8. Zhang YX, Zhou LY, Song ZQ, Zhang JZ, He LH, Ding Y. Primary antibiotic resistance of Helicobacter pylori strains isolated from patients with dyspeptic symptoms in Beijing: a prospective serial study. World J Gastroenterol. 2015; 21:2786-92.

9. Li H, Yang T, Tang H, Tang $X$, Shen Y, Benghezal M, et al. Helicobacter pylori infection is an infectious disease and the empiric therapy paradigm should be changed. Precis Clin Med. 2019;2:77-80.

10. Arévalo-Galvis A, Trespalacios-Rangel AA, Otero W, Mercado-Reyes MM, Poutou-Piñales RA. Prevalence of cagA, vacA, and iceA genes in $\mathrm{H}$. pylori strains isolated from Colombian patients with functional dispepsia. Pol J Microbiol. 2012;61:33-40.

11. Chauhan N, Tay ACY, Marshall BJ, Jain U. Helicobacter pylori vacA, a distinct toxin exerts diverse functionalities in numerous cells: an overview. Helicobacter. 2019;24:e12544.

12. Boquet $P$, Ricci V. Intoxication strategy of Helicobacter pylori vacA toxin. Trends Microbiol. 2012;20:165-74.

13. Gangwer KA, Shaffer CL, Suerbaum S, Lacy DB, Cover TL, Bordenstein SR. Molecular evolution of the Helicobacter pylori vacuolating toxin gene vacA. J Bacteriol. 2010;192:6126-35.

14. Louw J, Kidd M, Kummer A, Taylor K, Kotze U, Hanslo D. The relationship between Helicobacter pylori infection, the virulence genotypes of the infecting strain and gastric cancer in the African setting. Helicobacter. 2001; 6:268-73.

15. Hatakeyama M. Oncogenic mechanisms of the Helicobacter pylori cagA protein. Nat Rev Cancer. 2004;4:688-94.

16. Li N, Tang B, Jia YP, Zhu P, Zhuang Y, Fang Y, et al. Helicobacter pylori cagA protein negatively regulates autophagy and promotes inflammatory response via c-met-PI3K/Akt-mTOR signaling pathway. Front Cell Infect Microbiol. 2017;7:417.

17. Blaser MJ, Perez-Perez Gl, Kleanthous H, Cover TL, Peek RM, Chyou PH, et al. Infection with Helicobacter pylori strains possessing cagA is associated with an increased risk of developing adenocarcinoma of the stomach. Cancer Res. 1995;55:2111-5.

18. Román-Román A, Martínez-Carrillo DN, Atrisco-Morales J, Azúcar-Heziquio JC, Cuevas-Caballero AS, Castañón-Sánchez CA, et al. Helicobacter pylori vacA $\mathrm{s} 1 \mathrm{~m} 1$ genotype but not cagA or babA2 increase the risk of ulcer and gastric cancer in patients from southern Mexico. Gut Pathog. 2017:9:18.

19. Dunne C, Dolan B, Clyne M. Factors that mediate colonization of the human stomach by Helicobacter pylori. World J Gastroenterol. 2014;20:5610-24.

20. Gerhard M, Lehn N, Neumayer N, Borén T, Rad R, Schepp W, et al. Clinical relevance of the Helicobacter pylori gene for blood-group antigen-binding adhesin. Proc Natl Acad Sci U S A. 1999;96:12778-83.

21. Wang YK, Kuo FC, Liu CJ, Wu MC, Shih HY, Wang SS, et al. Diagnosis of Helicobacter pylori infection: current options and developments. World J Gastroenterol. 2015;21:11221-35.

22. lerardi E, Giorgio F, lannone A, Losurdo G, Principi M, Barone M, et al. Noninvasive molecular analysis of Helicobacter pylori: is it time for tailored first-line therapy? World J Gastroenterol. 2017;23:2453-8.

23. Tongtawee T, Kaewpitoon S, Kaewpitoon N, Dechsukhum C, Leeanansaksiri W, Loyd RA, et al. Diagnosis of Helicobacter pylori infection. Asian Pac J Cancer Prev. 2016;17:1631-5.

24. Belda S, Saez J, Santibáñez M, Rodríguez JC, Galiana A, Sola-Vera J, et al. Quantification of Helicobacter pylori in gastric mucosa by real-time polymerase chain reaction: comparison with traditional diagnostic methods. Diagn Microbiol Infect Dis. 2012;74:248-52.

25. Idowu A, Mzukwa A, Harrison U, Palamides P, Haas R, Mbao M, et al. Detection of Helicobacter pylori and its virulence genes (cagA, dupA, and vacA) among patients with gastroduodenal diseases in Chris Hani
Baragwanath academic hospital, South Africa. BMC Gastroenterol. 2019;19: 73.

26. Lottspeich C, Schwarzer A, Panthel K, Koletzko S, Russmann H. Evaluation of the novel Helicobacter pylori clarires real-time PCR assay for detection and clarithromycin susceptibility testing of $\mathrm{H}$. pylori in stool specimens from symptomatic children. J Clin Microbiol. 2007:45:1718-22.

27. Landis JR, Koch GG. The measurement of observer agreement for categorical data. Biometrics. 1977;33:159-74.

28. Holck S, Norgard A, Bennedsen M, Permin H, Norn H, Andersen LP. Gastric mucosal cytokine responses in Helicobacter pylori-infected patients with gastritis, peptic ulcers. Association with inflammatory parameters and bacteria load. FEMS Immunol Med Microbiol. 2003;36:175-80.

29. Molnar B, Szoke D, Ruzsovics A, Tulassay Z. Significantly elevated Helicobacter pylori density and different genotype distribution in erosions as compared with normal gastric biopsy specimen detected by quantitative real-time PCR. Eur J Gastroenterol Hepatol. 2008;20:305-13.

30. Wang J, Liu X. Correlation analysis between Helicobacter pylori infection status and tumor clinical pathology as well as prognosis of gastric cancer patients. Iran J Public Health. 2018;47:1529-36.

31. Ladeira MS, Bueno RC, Dos Santos BF, Pinto CL, Prado RP, Silveira MG, et al. Relationship among oxidative DNA damage, gastric mucosal density and the relevance of cagA, vacA and iceA genotypes of Helicobacter pylori digestive diseases and sciences. Dig Dis Sci. 2008;53:248-55.

32. Zhang C, Yamada N, Wu YL, Wen M, Matsuhisa T, Matsukura N. Comparison of Helicobacter pylori infection and gastric mucosal histological features of gastric ulcer patients with chronic gastritis patients. World J Gastroenterol. 2005;11:976-81.

33. Tang $Y L$, Gan RL, Dong BH, Jiang RC, Tang RJ. Detection and location of Helicobacter pylori in human gastric carcinomas. World J Gastroenterol. 2005; 11:1387-91.

34. Sarma A, Saikia L, Gogoi M, Yadav K. Molecular characterisation of virulent gene vacA in Helicobacter pylori clinical isolates from patients with gastroduodenal diseases in Assam, India. Indian J Med Microbiol. 2018;36: 178-85.

35. Harrison U, Fowora MA, Seriki AT, Loell E, Mueller S, Ugo-ljeh M, et al. Helicobacter pylori strains from a Nigerian cohort show divergent antibiotic resistance rates and a uniform pathogenicity profile. PLoS One. 2017;12: e0176454.

36. Belda S, Saez J, Santibáñez M, Rodríguez JC, Sola-Vera J, Ruiz-García M, et al. Relationship between bacterial load, morbidity and cagA gene in patients infected by helicobacter pylori. Clin Microbiol Infec. 2012;18:E251-3.

37. Sugimoto M, Zali MR, Yamaoka Y. The association of vacA genotypes and Helicobacter pylori-related gastroduodenal diseases in the Middle East. Eur J Clin Microbiol Infect Dis. 2009:28:1227-36.

38. Xiang Z, Censini S, Bayeli PF, Telford JL, Figura N, Rappuoli R, et al. Analysis of expression of CagA and VacA virulence factors in 43 strains of Helicobacter pylori reveals that clinical isolates can be divided into two major types and that CagA is not necessary for expression of the vacuolating cytotoxin. Infect Immun. 1995;63:94-8.

39. Kusters JG, Van Vliet AHM, Kuipers EJ. Pathogenesis of Helicobacter pylori infection. Clin Microbiol Rev. 2006;19:449-90.

40. González CA, Figueiredo C, Lic CB, Ferreira RM, Pardo ML, Liso JMR, et al. Helicobacter pylori cagA and vacA genotypes as predictors of progression of gastric preneoplastic lesions: a long-term follow-up in a high-risk area in Spain. Am J Gastroenterol. 2011:106:867-74.

\section{Publisher's Note}

Springer Nature remains neutral with regard to jurisdictional claims in published maps and institutional affiliations. 